\title{
Dynamic changes in quantitative features of human gastric lesions
}

\author{
Ventzeslav Enchev* \\ Department of Pathology, Third City Hospital, Sofia, Bulgaria
}

Jean Paul Rigaut

Laboratoire Universitaire d'Analyse d'Images en Pathologie Cellulaire, Hôpital Saint Louis, AIPC, 75475 Paris Cedex 10, France

Received 29 October 1994

Revised 20 November 1996

\begin{abstract}
Quantitative DNA, morphometric cellular and nuclear variables were evaluated in surgical biopsies from patients with various gastric lesions: chronic gastritis, chronic ulcers, adenomatous polyps (gastric adenomas), primary carcinomas and their corresponding lymph-node metastases. Paraffin-embedded tissue sections were studied by static cytophotometry (plug method), karyometry (measurements with a graduated eyepiece micrometer of the major and minor axes of the elliptic nuclear profiles, and calculation of profile areas), and measurements of cellular profiles (largest and smallest caliper diameters). Tissue lymphocytes from the same slide were used as diploid controls for the DNA evaluations.

An increase of both cellular and nuclear dimensions and DNA content was noted in all pathological tissues, as compared to normal mucosa; the highest values are found in primary gastric carcinomas. A progressive pattern increase of cellular and nuclear dimensions and of DNA content was observed through normal to cancerous tissues, chronic gastritis, chronic ulcers and adenomatous polyps (adenomas). Lymph-node metastases, in our study, had smaller nuclear (cellular) dimensions than primary cancers.
\end{abstract}

Keywords: Human gastric mucosa, cancer, gastritis ulcers, morphometry/karyometry, DNA cytophotometry

\section{Introduction}

The use of objective criteria in the evaluation of tissue sections may improve the reliability of gradings, and offers some new insights into oncogenetic evolution. In two reviews [11,12], several authors have described a progressive increase of nuclear dimensions and DNA content [9] in what seems to be a plausible pathway through metaplasia and increasingly severe grades of dysplasia to epithelial cancer. Another paper [13] reported the same trends in nuclear dimensions in a limited number of gastric biopsies, as was also the case in our preliminary studies $[3-5,7,8]$.

Such progressive changes cannot be easily demonstrated without the use of quantitation. We used both morphometric and DNA content variables. Only a few papers on the joint applications of these

\footnotetext{
${ }^{*}$ Corresponding author: Dr Ventzeslav G. Enchev, MD, Ph.D., Department of Pathology, Third City Hospital, 65, Miko Papo street, 1309 Sofia, Bulgaria.
} 
two methods on tissue sections in stomach lesions have been so far published [6,8]. Rigaut and Fringes [13] only evaluated nuclear size/shape gastric measures; the papers of Tosi et al. [14,15,17] reported on an increase of quantitative features in gastric metaplastic and dysplastic specimens using stereological and morphometrical methods.

This study presents quantitative results on 150 patients with normal, gastritic, ulcerous, polypous or cancerous stomach mucosae as a theoretical database of a consultation system for diagnosis of gastric lesions recently offered in the literature [6].

\section{Materials and methods}

\subsection{Biopsies and histological methods}

Paraffin-embedded tissue sections (thickness 10-15 $\mu \mathrm{m}$ ) from surgically biopsied patients were Feulgen-stained ( 1 hour hydrolysis in $5 \mathrm{~N} \mathrm{HCl}$, at room temperature after air drying), through a carefully standardized procedure, described elsewhere [8].

The diagnoses were made on consecutive, hematoxylin-eosin-stained, slides (thickness 4-5 $\mu \mathrm{m}$ ). The group of patients investigated consisted of 150 human specimens; 25 were found as having normal mucosae, while 30 had chronic gastritis with or without intestinal metaplasia; 25 chronic ulcers, 25 adenomatous polyps (gastric adenomas), and 25 primary carcinomas (among which 20 had lymphnode metastases). Five patients in each category (lymph-node metastases excluded) were studied cytospectrophotometrically. Cases with Menetrier's gastropathy were also excluded.

Morphometric and DNA content assessments were made at $1000 \times$ magnification on 160 gastric epithelial cellular profiles for each section (one per patient) by rotation of a graduated eyepiecemicrometer for morphometrical measurements and by measuring the transmission and calculating the extinction for static (absorption) cytospectrophotometry.

\subsection{DNA content evaluation}

The plug or Gore method for absorption cytophotometry was used (wavelength: $550 \mathrm{~nm}$, objective $100 \times$, ocular $10 \times$, Optowar 1.6 , condensor $1.30 \mathrm{n} \AA$ and immersion oil with refractive index at $\left.20^{\circ} \mathrm{C}=1.515\right)$ with an Opton-MPM 01 cytophotometer [8]. Nuclear profile DNA contents were expressed in Arbitrary Units (AU) and were plotted on frequency histograms using an equation given in the Appendix of this paper. DNA contents observed in 15 lymphocytic nuclear profiles from the same sample served as diploid controls (mean value $\pm 20 \% \mathrm{AU}$ ).

\subsection{Morphometry}

A graduated eyepiece micrometer was used [7]. The nuclei being spheroidal-shaped, the minor $\left(\mathrm{B}_{\mathrm{N}}\right)$ and major $\left(\mathrm{L}_{\mathrm{N}}\right)$ axes of their elliptic profiles were measured; the nuclear profile area was calculated. Cellular caliper diameters $\left(B_{c}\right.$ and $\left.L_{c}\right)$ of cellular profiles were also measured. Their areas were roughly estimated according to geometrical formulae described in the Appendix of this paper. Values observed in normal mucosae served as standard controls for evaluating other processes in the pathway from the normal to cancerous development. 


\subsection{Statistical processing}

All profile data were plotted on frequency histograms. Statistical comparisons were made by Wilcoxon-Mann-Whitney's U test.

No attempt was made at stereologically estimating the real three-dimensional size and DNA quantities of the cells and their nuclei.

\section{Results}

\subsection{Nuclear profile DNA content}

Pooled results are presented in Table 1 and Fig. 1.

In normal gastric mucosa, chronic ulcers, chronic atrophic gastritis with or without intestinal metaplasia and adenomatous polyps (adenomas), the DNA values are situated in the diploid and tetraploid ranges of the histogram. There is, however, a larger predominance of the apparently diploid peak in normal cases; in chronic ulcers, chronic gastritis and especially adenomatous polyps (gastric adenomas), a sizeable contribution of scattered values apparently higher than tetraploid was observed; in chronic hypertrophic gastritis (excluding Menetrier's gastropathy), the histograms often showed the presence of an additional peak in the hexaploid region.

Malignantly transformed ulcers (adenocarcinomas, arising from chronic gastric ulcers) often show values in the hypertetraploid region. DNA assessments may reach the octaploid range in malignantly transformed adenomatous polyps (gastric adenomas with a malignization).

DNA contents in the tetraploid and octaploid ranges are usual in primary carcinomas, but values up to apparently decaploid are observed in some cases.

Statistically significant separations are obtained between: normal mucosa versus atrophic gastritis with or without intestinal metaplasia $(p=.008)$, chronic ulcer with carcinoma $(p=.008)$, or adenocarcinomas of unknown origin $(p=.016)$; normal mucosa versus all gastrites $(p=.008)$, or all carcinomas $(p=.004)$; and all gastrites versus all carcinomas $(p=.006)$. No significant difference was found between normal mucosa versus hypertrophic gastritis, gastric adenomas with carcinomas or hypertrophic versus atrophic gastritis.

\subsection{Nuclear profile morphometric variables}

Pooled results are presented in Table 2 and Fig. 2.

Table 1

Nuclear DNA contents (arbitrary units). Means and standard deviations are for $n$ patients. For each patient, the DNA value was the mean of 60 nuclear profile measurements

\begin{tabular}{lccc}
\hline Histology & $n$ & \multicolumn{2}{c}{ DNA (AU) } \\
\hline Normal gastric mucosa & 5 & 32.8 & $(1.9)$ \\
Chronic atrophic gastritis & 5 & 37.2 & $(5.1)$ \\
Chronic hypertrophic gastritis & 5 & 39.5 & $(3.6)$ \\
Chronic gastric ulcer + carcinoma & 5 & 45.0 & $(5.0)$ \\
Adenomatous gastric polyp + carcinoma & 5 & $46.3(8.7)$ \\
Adenocarcinoma & 5 & $57.8(16.2)$ \\
\hline
\end{tabular}



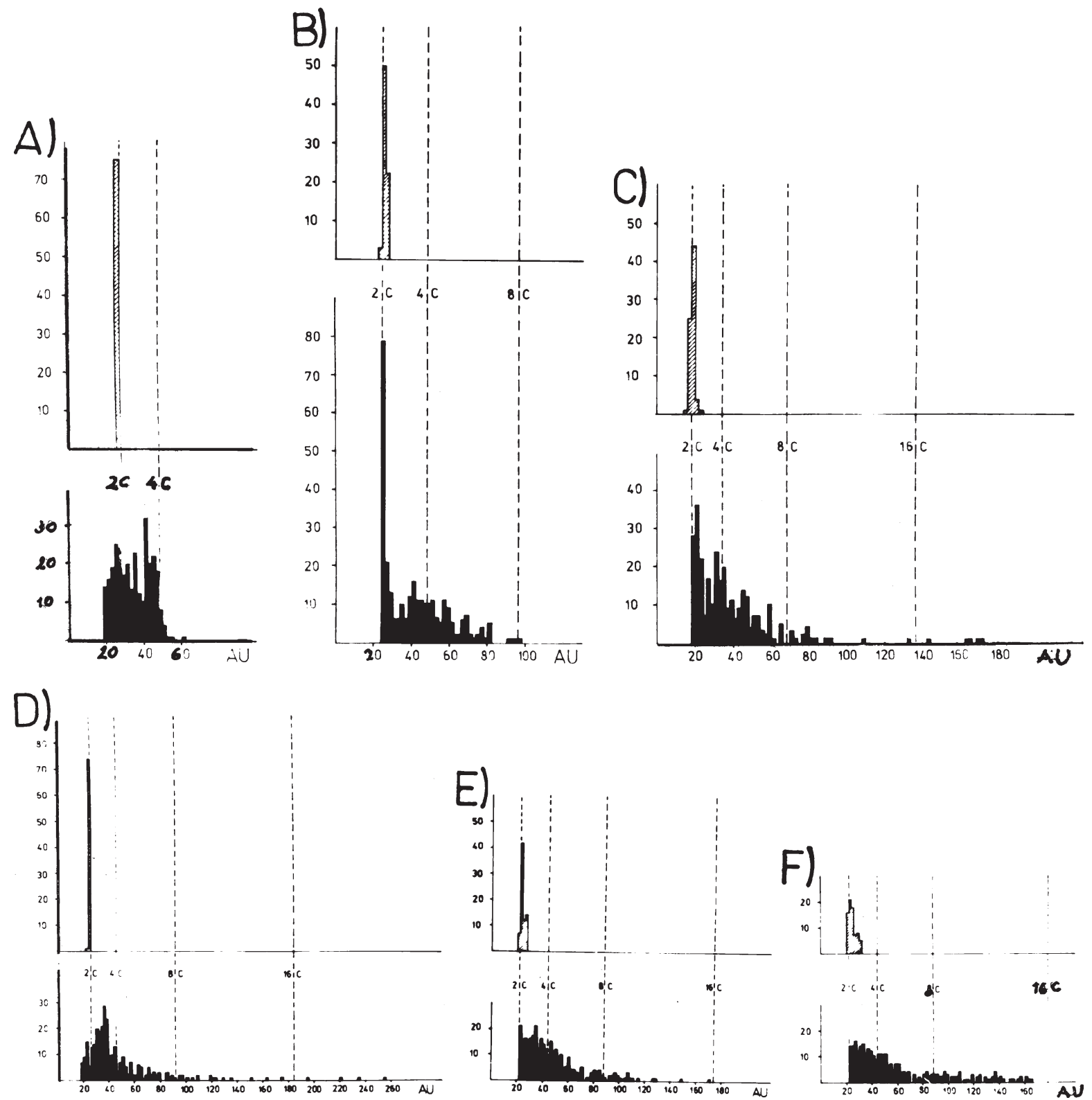

Fig. 1. Histograms of nuclear profile DNA contents, pooled between patients (arbitrary units). A: normal gastric mucosa; B: chronic atrophic gastritis; C: chronic hypertrophic gastritis; D: gastric ulcers with carcinoma; E: adenomatous gastric polyps with carcinoma; F: gastric adenocarcinomas.

In normal gastric mucosa, the histogram values of the minor elliptic axis $\left(\mathrm{B}_{\mathrm{N}}\right)$ lengths were in the 3-15 $\mu \mathrm{m}$ range, with a peak at 7-8 $\mu \mathrm{m}$. The major elliptic axis of the nuclear profiles $\left(\mathrm{L}_{\mathrm{N}}\right)$ are all in the $4-14 \mu \mathrm{m}$ range, with a peak at $9-10 \mu \mathrm{m}$; the nuclear profile area is thus in the $10-180 \mu \mathrm{m}^{2}$ range, with a peak at $50-63 \mu \mathrm{m}^{2}$.

In gastritic changed mucosae, there is no notable change in the length of the major axis, but the minor one is clearly greater than in the normal epithelium. 
Table 2

Karyometry: $\mathrm{B}_{\mathrm{N}}$ and $\mathrm{L}_{\mathrm{N}}$ are, respectively, the minor and major axes of the elliptical nuclear profiles. Means and standard deviations are for $n$ patients. For each patient, the parameter values were the means of 100 nuclear profile measurements

\begin{tabular}{llrr}
\hline Histology & $n$ & $\mathrm{~B}_{\mathrm{N}}(\mu \mathrm{m})$ & \multicolumn{1}{c}{$\mathrm{L}_{\mathrm{N}}(\mu \mathrm{m})$} \\
\hline Normal gastric mucosa & 25 & $7.16(.92)$ & $9.00(.74)$ \\
Chronic gastritis & 30 & $8.19(1.98)$ & $9.55(1.67)$ \\
Chronic gastric ulcer & 25 & $11.43(2.27)$ & $13.03(1.98)$ \\
Adenomatous gastric polyp & 25 & $12.22(2.67)$ & $14.31(3.25)$ \\
Primary gastric carcinoma & 25 & $15.78(.82)$ & $18.91(1.02)$ \\
Lymph-node metastasis & 20 & $14.16(1.04)$ & $15.96(1.04)$ \\
\hline
\end{tabular}
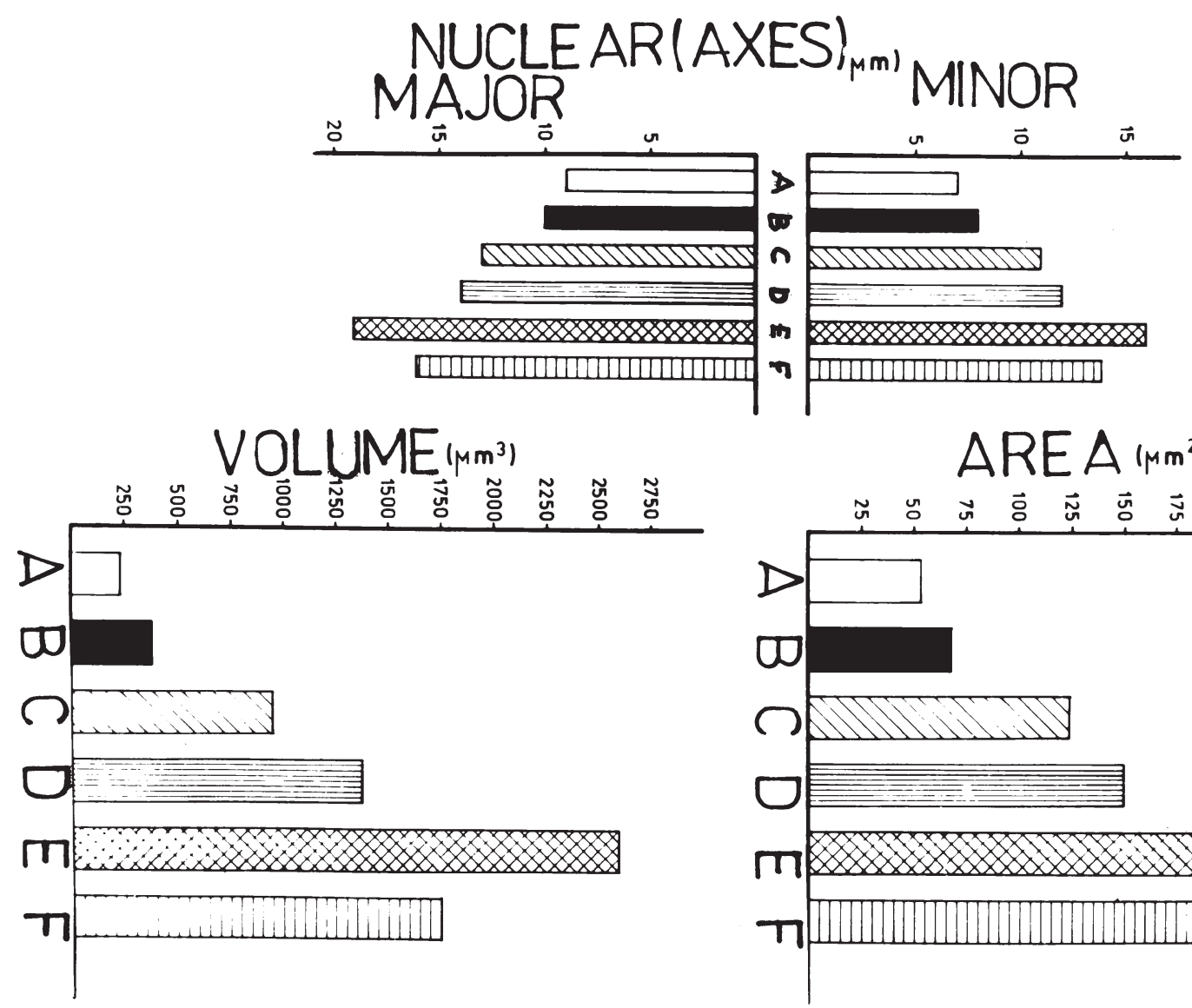

AREA $\left(\mathrm{mm}^{2}\right)$

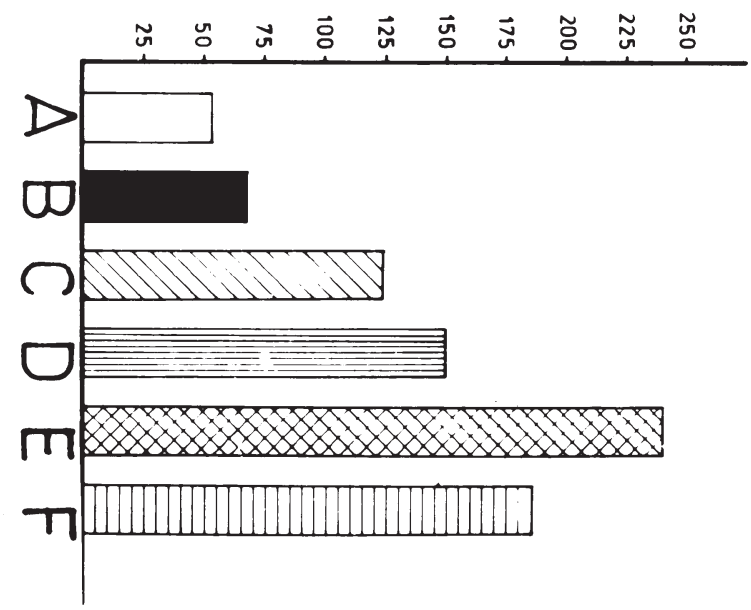

Fig. 2. Histograms of nuclear profile minor $\left(B_{N}\right)$ and major $\left(L_{N}\right)$ elliptic axes, pooled between patients. A: normal gastric mucosa; B: chronic gastritis; C: chronic gastric ulcers; D: adenomatous gastric polyps; E: primary gastric carcinomas; F: lymph-node metastases.

In chronic ulcers, the nuclear profile dimensions show mean and peak values which are rather similar to those of gastritis, but the variability between individual profile values is increased and the presence of some higher profiles is noted in some individual cases. 
Table 3

Cellular morphometry: $\mathrm{B}_{\mathrm{c}}$ and $\mathrm{L}_{\mathrm{c}}$ are, respectively, the minor and major caliper diameters of the cellular profiles. Means and standard deviations are for $n$ patients. For each patient, the parameter values were the means of 100 cellular profile measurements

\begin{tabular}{lccc}
\hline Histology & $n$ & $\mathrm{~B}_{\mathrm{c}}(\mu \mathrm{m})$ & $\mathrm{L}_{\mathrm{c}}(\mu \mathrm{m})$ \\
\hline Normal gastric mucosa & 25 & $11.08(1.20)$ & $13.57(1.49)$ \\
Chronic gastritis & 30 & $11.36(1.58)$ & $13.02(1.52)$ \\
Chronic gastric ulcers & 25 & $14.46(1.94)$ & $17.01(1.94)$ \\
Adenomatous gastric polyps & 25 & $15.76(3.53)$ & $18.41(4.56)$ \\
Primary gastric carcinomas & 25 & $20.27(1.23)$ & $24.61(1.30)$ \\
Lymph-node metastases & 20 & $17.05(1.29)$ & $19.49(1.41)$ \\
\hline
\end{tabular}

In adenomatous polyps (gastric adenomas), the size distributions resemble those in chronic ulcers, but with a lesser size variability between profiles and from one case to the other.

Carcinomas are characterized by the presence of higher peak values for features than any of the other lesions. Some very high profiles are observed, in addition, in most cases.

Pooled size histograms from lymph-node metastases show lower values for their peaks than carcinomas; the range seems to correspond to tetraploid DNA values.

\subsection{Cellular profile morphometric variables}

As shown in Table 3, the dimensions of cellular profiles also show a pattern of progressive change from normal to carcinoma.

The increase in size of the cells is most striking in carcinomas, where both major and minor caliper diameters are, on the average, about double that of normal. Here again, lymph-node metastases show lesser increases in size.

\section{Discussion}

Our results clearly show dynamic changes, both for nuclear sizes and DNA contents, in what could be a pathway from normal to cancerous gastric epithelium through hyperplastic processes (chronic gastritis with or without intestinal metaplasia), and lesions which are known to be associated with an increased risk of subsequent cancer (chronic ulcers and adenomatous polyps - adenomas). In the nasal epithelium, it has been shown [2] that progressive alterations also exist for parameters other than nuclear, and a grading based on this fact has given very good results [1].

As stated in another review [11], the presence of enlarged nuclei and increased DNA contents in epithelial lesions may represent an argument in favor of their "pre-cancerous" nature. This is clearly the case in gastric dysplasia, where measurements show usual values which are close to those of cancers. It is, however, interesting to observe that enlarged nuclei present in most chronic gastritis, in our own work, as was also noted by Rigaut and Fringes [13]. Such stereologically estimated lesions are not usually considered, in contrast to ulcers and adenomas, as truly "pre-cancerous". But an important question is whether they represent or not a required stage in gastric carcinogenesis. A similar problem has been encountered in the nasal epithelium, where cuboidal metaplasia already shows enlarged nuclei [12]. These facts may be interpreted as arguments in favor of a two-step model of carcinogenesis. In our work, some high nuclear profiles point to the presence, in some gastritic 
cases, of nuclei of ploidies higher than 4 C (in a region around 5-6 C) [19,20]. Such values, if they can be confirmed on whole nuclei, may represent critical changes required for a subsequent oncogenetic evolution.

In the present study, intermediate quantitative values were found for all quantities evaluated in chronic ulcers and adenomatous polyps (gastric adenomas). Tumours, arising from those lesions showed quantitative data similar, on the average, to those from tumours of unknown origin. Another paper noted that they have diploid and aneuploid cell populations [16].

Another interesting result is that lymph-node metastases showed smaller morphometric nuclear (cellular) values than cancers from which they had arizen. A possible interpretation is that clones of a particular ploidy are required for metastasis. More aggressive, potentially invasive clones of nearly normal ploidy (slight hyper-diploidy?) would be selected at the onset of invasive cancer and again later, when metastasis occurs. Alternatively, some of the smaller nuclei selected before the invasion would remain inside the tumour and be responsible for the final assault on lymph-nodes.

The progressive change in size of the cells is not proportional to that of their nuclei: the nuclear/cytoplasmic ratio increases from normal gastric mucosa to cancer [7].

The present work only deals with quantitative features from cellular and nuclear profiles. No simple relationship exists between the distributions of DNA from sectioned nuclei and the real distributions which would be observed if we could see three-dimensional nuclei. We used a rather large section thickness to minimize the frequency of nuclei not entirely contained in the sections. There is no doubt, however, that better separated peaks would appear on the DNA histograms if we could correct them for the effects of sectioning. A rather stereologically imperfect model has been proposed [10] for DNA from spheroidal nuclei. But here there are parallel, prolate, spheroidal nuclei, and no model exists for DNA in such a case, for which the correction would have to depend on the sectioning angle. It is also impossible to correct the size distributions to obtain the real three-dimensional bivariate (size/shape) ones. No direct calculations are really feasible on the frequency peaks, which do not necessarily reflect the maximal parameter values in contrast to spheroidal nuclei.

Finally, another review [18] noted that morphometry, stereology and image analysis will certainly represent one of the important future trends in oncology.

\section{References}

[1] M. Boysen, P. Marton, L. Pilström, L.A. Solberg and T. Torp, A simple and efficient method for objective discrimination between pseudostratified, metaplastic and dysplastic nasal epithelium, J. Microsc. 130 (1983), 99-106.

[2] M. Boysen and A. Reith, Stereological analysis of nasal mucosa. III. Stepwise alterations in cellular and subcellular components of pseudostratified, metaplastic and dysplastic epithelium in nickel workers, Virch. Arch. B40 (1982), 311-325.

[3] V.G. Enchev, Quantitative evaluation of the cell changes in stomach cancer - in Russian, C. R. Acad. Bulg. Sci. 36 (1983), 289-292.

[4] V.G. Enchev, Gastric carcinomas and their lymphogeneous metastases in cytomorphometric expression, Gegenbaurs Morph. Jahrb. 130 (1984), 565-571.

[5] V.G. Enchev, Quantitative extraction of nuclear parameters in patients with different gastric lesions, in: Quantitative Image Analysis in Cancer Cytology and Histology, J.Y. Mary and J.P. Rigaut, eds, Elsevier Publishers, AmsterdamNew York-Oxford, 1986, pp. 324-326.

[6] V.G. Enchev, J. Angelova and J. Peneva, Consultation system for diagnosis of gastric lesions, Anal. Quant. Cytol. Histol. 17 (1996) (in press).

[7] V.G. Enchev and R.D. Raichev, Zytomorphometrische Untersuchungen bei normaler Magenschleimhaut, präkanzerösen Krankheiten und Magenkrebs, Arch. Geschwulstforsch. 52 (1982), 641-647.

[8] V.G. Enchev and K.G. Tsanev, Comparative cytomorphometric and cytospectrophotometric investigations of gastric lesions, Arch. Geschwulstforsch. 55 (1985), 37-46. 
[9] R.B. Longmore and J. Cowpe, Nuclear area and Feulgen DNA content of normal and abnormal oral squames, Anal. Quant. Cytol. 4 (1982), 33-38.

[10] R.W. McCready and J.M. Papadimitriou, An analysis of DNA cytophotometry of tissue sections in a rat liver model, Anal. Quant. Cytol. 5 (1983), 117-123.

[11] J.P. Rigaut, Karyometry on sections from dysplastic and cancerous tissues, in: Quantitative Image Analysis in Cancer Cytology and Histology, J.Y. Mary and J.P. Rigaut, eds, Elsevier Publishers, Amsterdam-New York-Oxford, 1986, pp. 207-222.

[12] J.P. Rigaut, M. Boysen and A. Reith, Karyometry of pseudostratified, metaplastic and dysplastic nasal epithelium by morphometry and stereology. 2. Automated image analysis (IBAS) of the basal layer of nickel workers, Path. Res. Pract. 180 (1985), 151-160.

[13] J.P. Rigaut and B. Fringes, Karyometry, with stereological estimations of human gastric dysplasia, Acta Stereol. 412 (1985), 231-235.

[14] P. Tosi, J.P.A. Baak, P. Luzi, C. Miracco, R. Lio and P. Barbini, Morphometric distinction of low- and high-grade dysplasias in gastric biopsies, Hum. Pathol. 20 (1989), 839-844.

[15] P. Tosi, M.I. Filipe, J.P.A. Baak, P. Luzi, G. Santopietro, V. Sforza and T. Megha, Morphometric definition and grading of gastric intestinal metaplasia, J. Pathol. 161 (1990), 201-208.

[16] P. Tosi, L. Leoncini, M. Cintorino, C. Vindigni, C. Miracco, S. Nuti, E. Pinto, A. di Stefano and G. Ceverini, Flow cytometric analysis of DNA ploidy pattern from deparaffinized formalin-fixed gastric cancer tissue, Intern. J. Cancer 42 (1988), 868-871.

[17] P. Tosi, P. Luzi, J.P.A. Baak, C. Miracco, C. Vindigni, R. Lio and P. Barbini, Gastric dysplasia: a stereological and morphometrical assessment, J. Pathol. 152 (1987), 83-94.

[18] M. Tubiana, The prospects of morphometry and image analysis in oncology, in: Quantitative Image Analysis in Cancer Cytology and Histology, J.Y. Mary and J.P. Rigaut, eds, Elsevier Publishers, Amsterdam-New York-Oxford, 1986, pp. 387-397.

[19] H. Weiß, W. Gibel, H.J. Gütz and G. Wolff, Möglichkeiten des Einsatzes der Impulszytophotometrie bei der Frühdiagnostik des Magenkarzinoms, Dtsch. Gesundh.-Wesen 28 (1973), 1930-1935.

[20] H. Weiß, G.P. Wildner, H.J. Gütz, G. Steinhoff and St. Tannenberger, DNA distribution patterns of preneoplastic cells and their interpretation (stomach and cervix uteri), Oncology 38 (1981), 210-218.

\section{Appendix}

Nuclear (cellular) areas $\left(\mathrm{A}_{\mathrm{N}}, \mathrm{A}_{\mathrm{c}}\right)$ were calculated according to the geometrical formula:

$$
\mathrm{A}=\frac{\pi}{4} \times \mathrm{L} \times \mathrm{B}
$$

where $\mathrm{A}=$ area, $\mathrm{L}=$ Longus (major) nuclear/cellular axis length, $\mathrm{B}=$ Brevis (minor) nuclear/cellular axis length.

Nuclear (cellular) volumes $\left(\mathrm{V}_{\mathrm{N}}, \mathrm{V}_{\mathrm{c}}\right)$ were also calculated as previously described [7] according to the formula:

$$
\mathrm{V}=\frac{\pi}{6} \times \mathrm{L} \times \mathrm{B}^{2}
$$

where $\mathrm{V}=$ volume, $\mathrm{L}$ and $\mathrm{B}-$ the same designations described above.

Nuclear DNA Content Assessments were calculated in Arbitrary Units (AU) according to the formula:

$$
\mathrm{AU}=\frac{\mathrm{E} \times \mathrm{A}}{\mathrm{F}},
$$

where $\mathrm{E}=$ extinction, $\mathrm{A}=$ area, $\mathrm{F}=$ factor for correction of DNA Content Values taken out from tables furnished by Firma-Producer of Cytophotometer "Opton-MPM 01", Germany. 


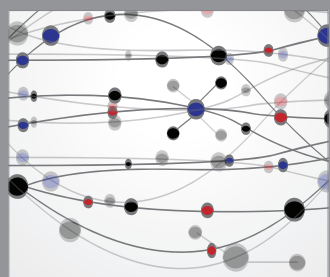

The Scientific World Journal
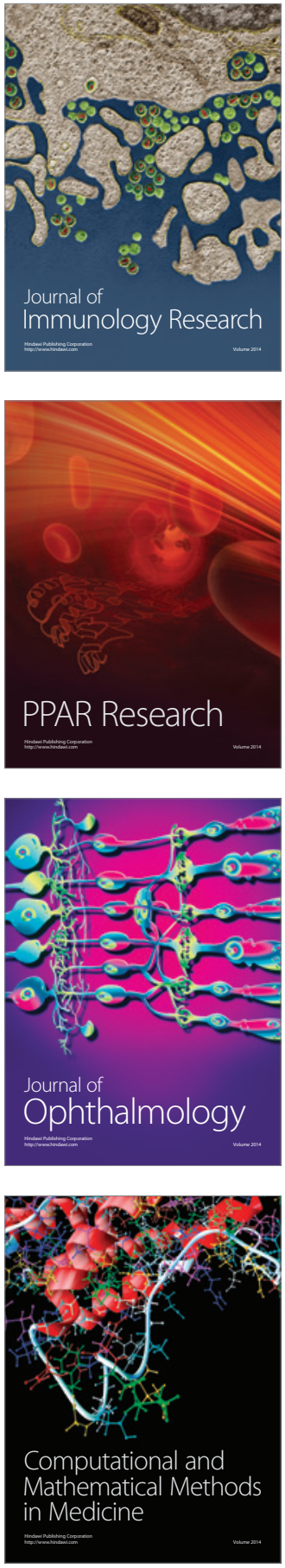

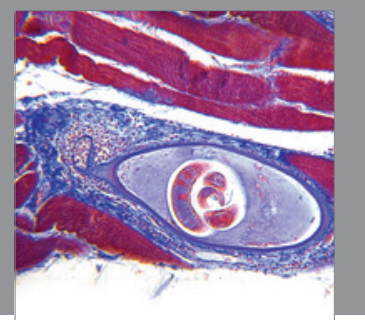

Gastroenterology

Research and Practice
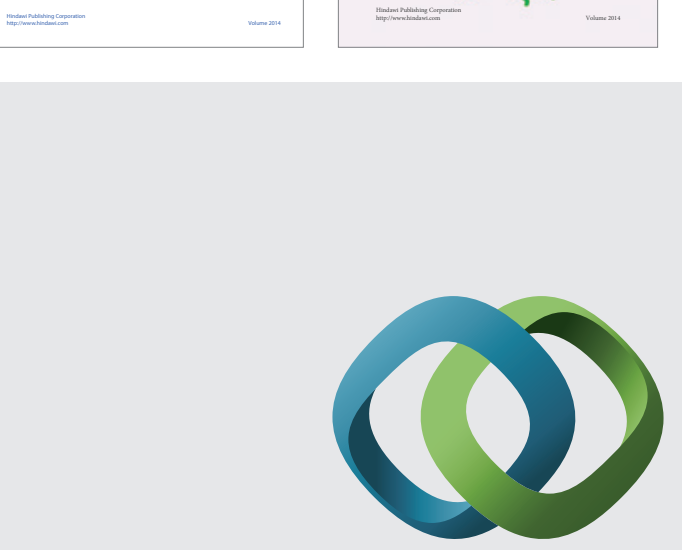

\section{Hindawi}

Submit your manuscripts at

http://www.hindawi.com
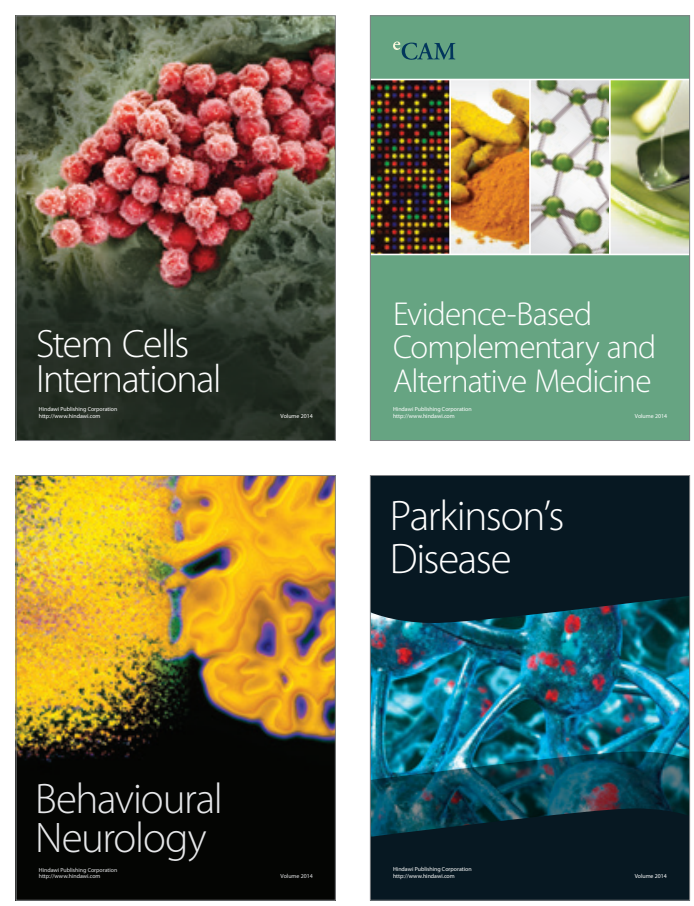

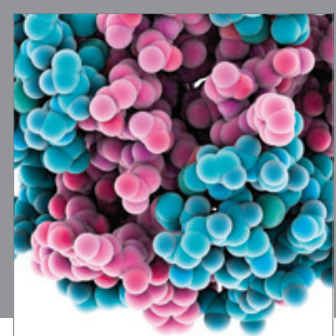

Journal of
Diabetes Research

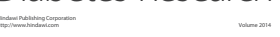

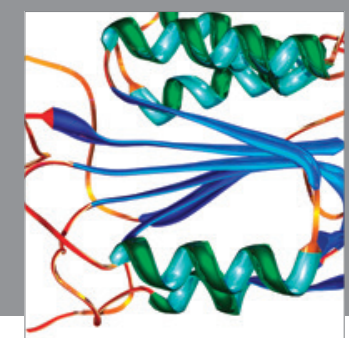

Disease Markers
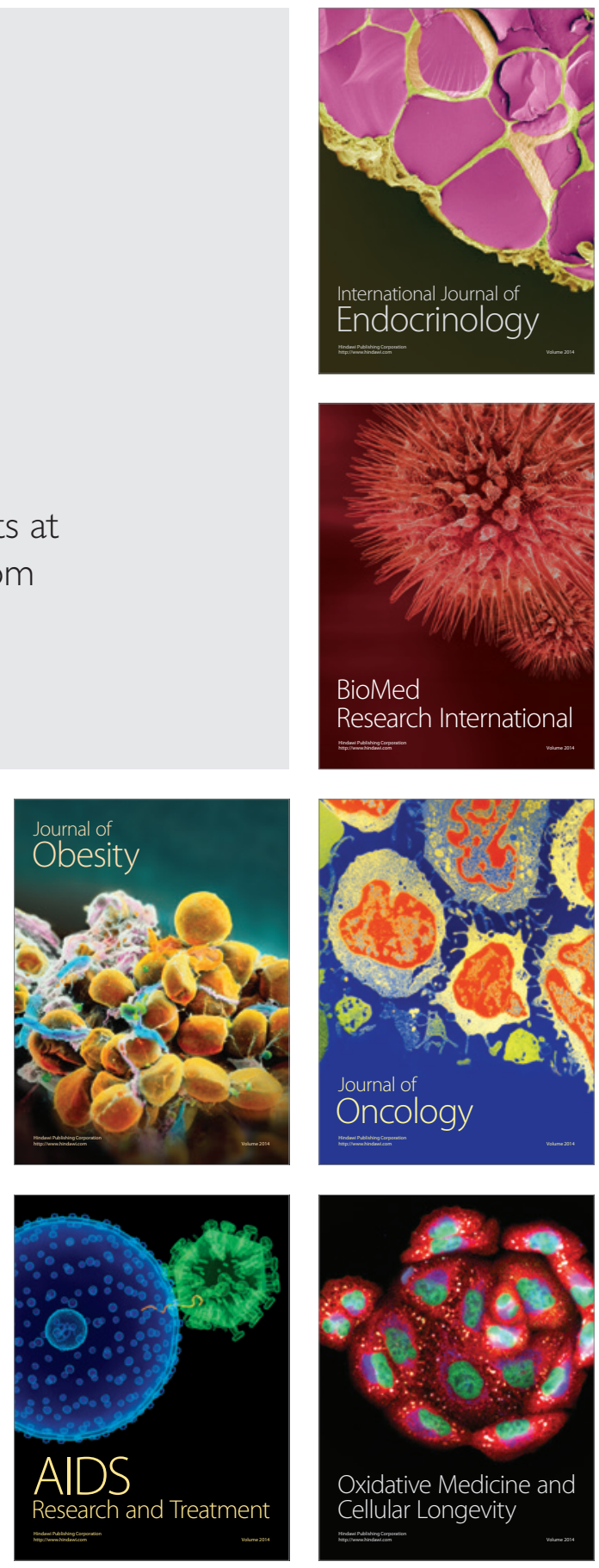